\title{
BERKELEY ON OTHER MINDS
}

\section{Charles Byron Cross}

In section 145 of A Treatise Concerning the Principles of Human Knowledge George Berkeley offers an account of how one might justify the claim that there are minds other than one's own. According to this account, if a person perceives ideas of a certain sort, then there is an external mental substance, i.e., a mind, of which these ideas are "effects or concomitant signs."I On the other hand, in section 18 Berkeley argues against the view that perceiving ideas provides a criterion for the existence of external material substances, i.e., physical or corporeal objects. After explicating the arguments in sections 145 and 18 , respectively, I will show that if one holds that Berkeley's attack in section 18 is sound, then one must reject Berkeley's own argument in section 145 .

Section 1.45 of the Principles encapsulates Berkeley's view of how one mind knows about other minds:

From what has been said it is plain that we cannot know the existence of other spirits otherwise than by their operations, or the ideas by them excited in us. I perceive several motions, changes, and combinations of ideas that inform me that there are certain particular agents, like myself, which accompany them and concur in their production. Hence the knowledge I have of other spirits is not immediate, as is the knowledge of my ideas, but depending on the intervention of ideas, by me referred to agents or spirits distinct from myself, as effects or concomitant signs. (p. 3211)

We may set a context for this passage as follows: suppose I say to myself, "There are mincls other than my own," and then pause and ask myslef, "How do I know this to be true?" According to Berkeley, the appropriate answer is, "I know that $1(\mathrm{a}), I(\mathrm{~b})$, and $I(\mathrm{c})$ are true, hence $I(d)$ is true and I an justified in believing so," where $1(a), l(b), l(c)$, and $1(d)$ are: 
1(a) I am mind.

l(b) I perceive certain ideas $x_{1}, x_{2}, . . . x_{n}$ of the sort $C$.

I(c) If a mind $M_{1}$ perceives ideas of the sort $c$, then there exists a mind $M_{2}$, distinct from $M_{1}$, of which the ideas are "effects or concomitant signs."

ergo 1(d) There exists a mind, distinct from me, of which $x_{1}, x_{2}, \ldots ., x_{n}$ are "effects or concomitant signs."

- There are at least three things about this argument which warrant explanation. First of all, let us note that Berkeley used 'idea' to denote that which is perceived; hence tables, chairs, the moon, etc., as well as freedom, squareness, and redness are all ideas in this sense. For the purposes of this discussion, we shall ignore the problems associated with Berkeley's usage of the word 'idea.'

Secondly, let us note that premise $l(c)$ begins with "If I perceive ideas of the sort $C$, . . " rather than "If I perceive the ideas $x_{1}, x_{2}, . . . x_{n}, . . . . "$ The reason for this may best be illustrated by an example: suppose (taking Berkeley's view of perception) I perceive a certain pattern of ideas consisting of a man speaking in English in an intelligible and coherent way, and $I$ conclude that there is another mind which caused me to perceive the man and his linguistic behavior. But what was most relevant to my conclusion in this scenario was that I perceived some man uttering some sequence of English sentences, not strictly that I perceived this man uttering that sequence of English sentences. Hence I drew the conclusion because I perceived ideas of a certain sort, i.e., because the ideas conformed to the general pattern "man speaking coherently in English." My principle of inference was not "If I perceive this man uttering these sentences, then there exists another mind"; rather, it was "If I perceive a man uttering coherent English sentences, then there exists another mind." of course the problem of how Berkeley (or anyone else) could establish which sorts of ideas imply the existence of another mind is very complex, and $I$ do not propose to address that problem here.

Thirdly, one might object to my use of "I perceive certain ideas $x_{1}, x_{2}, . . ., x_{n} . . . "$ in $1(a)$ instead of Berkeley's "I perceive several motions, changes, and combinations of ideas." But Berkeley's view is that the objects of perception are all and only ideas, hence Berkeley's "motions, changes, and combinations of ideas" are perceived if and only if they are themselves ideas. 
of course there are serious problems about calling a collection or combination of ideas an idea, but Berkeley's view is that one may do so, and I shall not deal further with the issue here.

In section 18 of the Principles Berkeley attacks one kind of justification for belief in material substance:

It remains therefore that if we have any knowledge at all of external things, it must be by reason, inferring their existence from what is immediately perceived by sense . . . I say it is granted on all hands (and what happens in dreams, frenzies and the like, puts it beyond dispute) that it is possible we might be affected with all the ideas we have now, though no bodies existed without resembling them. Hence it is evident the supposition of external bodies is not necessary for the producing our ideas; since it is granted that they are produced sometimes, and might possibly be produced always in the same order we see them in at present, without their

We may set the context for this passage much as we did for section 145: suppose I say to someone, "There are external material substances," and the other person replies, "How do you know"? Berkeley claims that it is not acceptable to reply, "I know that $2(d)$ is true because I know that $2(a), 2(b)$, and $2(c)$ are true"; where $2(a), 2(b), 2(c)$, and $2(d)$ are as follows:

2(a) I am a mind.

2(b) I perceive certain ideas $y_{1}, y_{2}, . . ., y_{m}$ of the sort $S$.

2(c) If a mind $M$ perceives ideas of the sort $S$, then there is some material substance which caused $M$ to perceive these ideas.

ergo $2(d)$ There is some material substance which caused me to perceive $\mathrm{y}_{1}, \mathrm{y}_{2}, \ldots ., \mathrm{y}_{\mathrm{m}}$.

The role of "of the sort $S$ " in this argunent is identical to that of "of the sort $C$ " in the first argument, except that ideas of the sort $S$ will be ideas such as "a firm, red, tasty, fragrant apple" or "a hard, heavy, silver colored sphere."

Berkeley attacks 2(a)-2(d) in section 18 by appealing to the following argument: 
3 (a) For any subset $D$ of our ideas, it is possible for the elements of $D$ to be imprinted on a dreaming or frenzied person's mind.

3(b) The imprinting of ideas on a dreaming or frenzied mind need not be caused by any external material substance.

3 (c) If $3(a)$ and $3(b)$, then for any subset $D$ of our ideas, it is possible that there exist a mind $M_{0}$ such that $M_{0}$ perceives the members of $D$, but no material substance causes $M_{0}$ to perceive any member of $D$.

ergo $P$ For any subset $D$ of our ideas, it is possible that there exist a mind $M_{0}$ such that $M_{0}$ perceives the members of $D$ but no material substance causes $M_{O}$ to perceive any member of $D$.

Clearly, $P$ contradicts premise $2(c)$, since $P$ says that the existence of a material substance is not a necessary condition for the perception of any idea, including ideas of the sort $\mathrm{S}$.

I will now show that given the above argument for $P$, and given Berkeley's assumptions about perception, one must reject the argument from section 145 as we 11 as the argument attacked in section 18. I will proceed as follows: (i) I will show that if one accepts the argument for $P$, then one must accept $P^{\prime}$, where $P^{\prime}$ is as follows:

$P^{\prime}$ For any subset $D$ of our ideas, it is possible that there exist a mind $M_{0}$ such that $M_{0}$ perceives each member of $D$, but no mental substance external to $\mathrm{M}_{0}$ causes or concurs in Mo's perception of the members of $D$.

And ( $i i)$ I will show that $\mathrm{P}^{\prime}$ undermines the argument from section 145 .

A crucial feature of the argument from $3(a), 3(b)$, and $3(c)$ to $P$ is the fact that Berkeley uses the examples of "dreams, frenzies, and the like" to prove his point. In particular, he notes that in such cases the perception of ideas need not be caused by external matter, even on the view of the materialists. But in the case of a dream or frenzy it may also happen that no external mental substance causes an idea to be perceived, as when one dreains about carrying on a conversation with someone else." Hence we may assert the following: 
$3(\mathrm{~b})^{\text {* }}$ The imprinting of an idea on a dreaming or frenzied mind need not be caused by any external mental substance.

Hence one may draw a conclusion parallel to Berkejey's conclusion in section 1.8 , viz, it is possible I might be affected with all the ideas I have now, though no minds existed outside me causing these ideas or exciting them in me. In other words, we have the following parallel. to premise $3(\mathrm{c})$ above:

$3(c) *$ If $3(a)$ and $3(b)$, then for any subset $D$ of our ideas, it is possible that there exist a mind $M_{0}$ such that $M_{0}$ perceives each member of $D$, but no mental substance external to $M_{0}$ causes or concurs in $M_{0}$ 's perception of the members of $D$.

Clearly, if $3(a), 3(b) *$, and $3(c) *$, then $P^{\prime}$ follows; thus if one accepts the argument for $P$, then one must accept $P^{\prime}$ as well, since we arrived at $3(b) *$ and $3(c) *$ on the basis of Berkeley's argument for $P$ and $a$ few observations concerning dreams or hallucinations in which one is conversing with someone else. But p' contradicts premise $1(\mathrm{c})$, just as $\mathrm{P}$ contradicted premise $2(c)$; that is $\mathrm{P}^{\prime}$ says that the existence of an external mental substance is not a necessary condition for the perception of any idea, including, of course, ideas of the type $c$.

One might object that it is ad hoc to make my point in this paper by using a parenthetical remark which, perhaps, Berkeley need not have made, viz.". . . and what happens in dreams, frenzies and the like, puts it beyond dispute. . . " My response is that Berkeley's appeal. to "dreams, frenzies, and the like" is no mere parenthetical remark; the general acceptance during the modern period of a Cartesian or quasi-Cartesian problem of dreams and hallucinations was the very reason why $P$ was "granted on all hands" during Berkeley's lifetime.

What all of this comes to is that Berkeley cannot have it both ways; that is, he cannot reject a representational account of knowledge of external objects yet hold to a representational account of knowledge of other minds. Consequently, Berkeley's imnaterialism leads irrevocably to solipsism, where solipsism is taken here to mean the inability to justify, and hence the inability to know, that there are minds other than one's own. Needless to say, this is one result that Berkeley most surely hoped to avoid. 5

University of 'l'exas, Austin 
${ }^{1}$ George Berkeley, A Treatise Concerning the Principles of Human Know̄ledge, ed. Colin Murray Turbayne, (New York: Bobbs-Merrili Company, Inc., 1970), p. 324.

2 Ibid.

${ }^{3}$ Ibid. , p. 254 .

"One might object that in this argument, as well as in Berkeley's argument from section 18, the difference between imagined and perceived ideas has been conveniently ignored, i.e., the term "imprinted on the mind" should mean one thing for perceived ideas and quite another for imagined ideas. I suppose that although Berkeley claims that imagined ideas are "less vivid" than perceived ideas (cf. Principles section 33), he would reply to this objection by claiming that some "dreams, frenzies, and the like" are so vivid that the imagined ideas involved are virtually indistinguishable from perceived ideas, as in Descartes' dreams about sitting at his desk writing. Hence (Berkeley might argue) even if all perceived ideas had material causes, one could not know that some particular idea had a material cause since that idea might only be a very vivid imagined idea. In other words, premise $2(\mathrm{c})$ might be true, but one could never know that it was true.

${ }^{5}$ In writing this paper I profited very much from conversations with Greg Gelvin and Edwin Allaire. 